\title{
A OBSERVAÇÃO DO ENSINO DA INCLUSÃO SOCIAL ATRAVÉS DA INTERPRETAÇÃO TEXTUAL E AUDIOVISUAL
}

\author{
Iago Martins Ramos $^{1}$
}

RESUMO: O presente trabalho se trata de um relato de experiência do discente Iago Martins Ramos da disciplina Estágio em Ensino de Leitura de Letras UFC. A observação ocorreu em duas classes de $7^{\circ}$ ano do Ensino fundamental II na Escola Ari de Sá Cavalcante. O objetivo desde trabalho, além do relato de experiência, é analisar a performance do professor referente aos processos de leitura e aquisição de conhecimento, e analisar o material didático estudado e a reação dos alunos frente aos processos e técnicas de leitura e suas atividades. Durante dois dias de observação, houveram discussões acerca dos seguintes temas: inclusão sociais e formação de consciência crítica perante atos como racismo e preconceito social. Essas discussões se deram devido às atividades de leitura e interpretação de recursos textuais e audiovisuais, como o texto retirado do livro didático da escola "Adolescente com autismo surpreende seus pais ao escrever uma carta profunda e sensível sobre pessoas com autismo", como também o livro paradidático "A mala de Hana" (Levine, Karen), que tem sua temática voltada para o nazismo e as dificuldades sociais vividas pelos judeus na Europa; além do filme "A vida é bela", que também tem sua temática relacionada ao nazismo durante a Segunda Guerra Mundial. As aulas observadas tiveram como objetivo/expectativas de aprendizagem: a interpretação textual, em que os alunos leem e interpretam textos, realizando leituras inferenciais; utilização do dicionário para eximir dúvidas quanto ao vocabulário; reflexão sobre a importância da igualdade social; reconhecimento de informações explícitas e implícitas do texto por meio de palavras e expressões; e a intertextualidade trabalhada em diferentes textos e recursos audiovisuais sobre a mesma temática. Quanto ao conteúdo linguístico, o objetivo principal era analisar a morfossintaxe do sujeito e revisar as classes gramaticais que podem exercer a função de sujeito.

Palavras-chave: Estágio. Ensino de leitura. Fundamental II. língua portuguesa. Interpretação textual. Inclusão social. Análise morfossintática do sujeito.

\section{INTRODUÇÃO}

\section{1 $\mathrm{A}$ instituição}

Fundada em 1961, de natureza particular, localizado na Avenida Washington Soares, 3737, em Fortaleza - CE, o colégio Ari de Sá Cavalcante, o qual escolhi, é a instituição na qual estudei desde minha infância à minha conclusão do ensino médio. A escola aceita alunos desde os 3 anos de idade ao Ensino Médio. A instituição possui

\footnotetext{
${ }^{1}$ Graduado em Letras Licenciatura - Português/Espanhol pela Universidade Federal do Ceará em turno integral (UFC), 2021. Professor em Escola de Línguas e Cultura Inglesa de Fortaleza LTDA. E-mail: iagomartinns@gmail.com.
} 
três sedes, localizada nos bairros Água Fria, Aldeota e Centro de Fortaleza. A escola conta com mais de 30 professores ao todo, além de diretores, coordenadores, psicólogos, psicopedagogos, todos empenhados em desenvolver a formação integral do aluno e de suas potencialidades intelectuais, afetivas e motoras. Além disso, a escola visa a formação da consciência social e visão histórica e crítica da sociedade, através da conscientização dos direitos e deveres enquanto cidadão. Além das visões críticas sociais, a escola propõe ao aluno a oportunidade de usar a da sabedoria humana e da tecnologia científica como instrumentos de ação modificadora das relações entre os homens e das condições de vida do ser humano. Através do desenvolvimento do espírito científico do aluno, postura autônoma, crítica e criativa e por meios da proximidade com o real e da ligação teórico-prática, os alunos promovem o processo de ensino-aprendizagem. O professor, por sua vez, é um elemento catalisador do processo do qual o aluno é o centro.

\subsection{Iniciando a investigação}

No dia treze e quatorze de junho, dia em que comecei minha investigação discente, encontrei na sala dos professores minha antiga professora do ensino fundamental II, a qual é a professora ministrante das aulas observadas, além de outros professores de outras disciplinas e coordenadores durante minha passagem pela fase discente escolar nessa instituição. Ao reencontrá-los, tive a oportunidade de conversar sobre suas crenças para com o ensino e sobre a aplicação de suas metodologias. Também, tive contato com a coordenadora de ensino, chefe responsável pelo cronograma escolar e administração dos professores dos ensinos fundamental I e II. Com ela pude sondar as turmas as quais não estavam em período de prova bimestral e consegui localizar duas turmas do $7^{\circ}$ ano, durante o período matutino, a qual eu poderia realizar minha observação por duzentos e cinquenta minutos de aula, período que corresponde à cinco aulas, três geminadas das sete e dez às dez e cinquenta da manhã em no dia treze e outras duas aulas geminadas das sete e dez às oito e cinquenta da manhã no dia quatorze. As turmas têm em média de trinta a quarenta alunos por sala, onde os alunos são organizados em sete fileiras horizontais por sete fileiras verticais. As salas são espaçosas, climatizada com ar-condicionado e dispõe de projetor, computador, cinquenta carteiras, lousa branca com tela para projetor para proporcionar um melhor aprendizado com diversos recursos oferecidos pela instituição.

As aulas que escolhi foram referentes à Língua Portuguesa, porém focadas na interpretação textual e seus processos de leitura e análises morfossintáticos. As turmas analisadas foram as salas do $7^{\mathrm{O}_{02}}$ e $7^{\circ}{ }^{\circ} \mathrm{O}$, cujos grupos possuem aulas de Língua Portuguesa - Interpretação Textual, nas terças e quartas-feiras, dias os quais utilizei para minha investigação. Nessas aulas, o capítulo que foi trabalhado era o ro Diferença que ensina, apresentado no livro adotado de Língua Portuguesa - SAS, Gramática: teoria e atividades - FTD. Neste capítulo é trabalhado como conteúdo linguístico a morfossintaxe do sujeito, através de atividades pré-determinadas pelo livro voltadas à análise linguística; como também, na parte de interpretação textual é trabalhada a temática da inclusão social através de dois textos: I. Adolescentes com 
autismo surpreende seus pais ao escrever uma carta profunda e sensível sobre pessoas com autismo" e 2. Inclusão Social. É apresentado, também, reflexões sobre o livro

paradidático da etapa "A mala de Hana" (Levine, Karen), que tem sua temática voltada para o nazismo e as dificuldades sociais vividas pelos judeus na Europa. Além do mais, o filme "A vida é bela", foi usado como recurso audiovisual extra, que também tem sua temática relacionada ao nazismo durante a Segunda Guerra Mundial. Com estes recursos, a aprendizagem tem como objetivo a interpretação textual, momento em que os alunos leem e interpretam textos, realizando leituras inferenciais; a utilização do dicionário para eximir dúvidas quanto ao vocabulário; a reflexão sobre a importância da igualdade social; o reconhecimento de informações explícitas e implícitas do texto por meio de palavras e expressões; e a intertextualidade trabalhada em diferentes textos e recursos audiovisuais sobre a mesma temática. Quanto ao conteúdo linguístico, o objetivo principal era analisar a morfossintaxe do sujeito e revisar as classes gramaticais que podem exercer a função de sujeito, recapitulando os conteúdos estudados anteriormente. Todos esses processos foram realizados através da fixação do conteúdo estudado em sala por meio de correções de atividades, revisando os aspectos linguísticos analisados junto com explicações do conteúdo.

\subsection{Os dias de observação, seus processos e enfoques}

O período de observação durou dois dias, pois a semana seguinte daria início ao processo de avalição semestral, logo, foi necessário dividir a atenção para duas turmas que ainda estavam concluindo seu cronograma escolar, o último capítulo a ser visto seria o dez, capítulo referente ao material de minha investigação. A professora ministrante das turmas é a mesma, pois ela é a única responsável especificamente para a disciplina de Língua Portuguesa - Interpretação Textual para a série observada. Tendo em vista as considerações anteriores, em minha investigação, separei como enfoque três fatores: I. uma análise e apreciação crítica dos fatos do exercício docente; 2. O corpo discente, mais precisamente oito alunos, quatro em cada turma, com tempo reservado de 3 minutos para cada um em diferentes localidades em sala; e 3. O material didático e recursos extras utilizados em sala para otimizar os processos de aprendizagem.

\section{I.I A docente}

Ela é formada em pedagogia pela Universidade Federal do Ceará (UFC) com participação em um Programa Especial de Treinamento (PET) em Educação Especial. A professora trabalhou em escola particular bairrista por sete anos no Ensino Fundamental I. Após uns anos nessa escola, surgiu a oportunidade de substituição de uma professora no colégio Ari de Sá Cavalcante no $4^{\underline{0}}$ ano do Ensino Fundamental I. Desde então, a professora se estabeleceu na instituição como professora polivalente do

Fundamental I. Com o passar do tempo e desenvolvimento profissional da professora, a escola ofereceu a oportunidade de assumir as turmas do $7^{\circ}$ ano do Ensino Fundamental II, pois sua didática e preocupação com a formação crítica e científica 
dos alunos chamou a atenção da escola. Ela realiza a profissão de ministrante há 25 anos e, devido à doença crônica nas cordas vocais, sua jornada de trabalho é de apenas dois dias seguidos durante o período matutino.

Durante o período reservado por mim para a apreciação do exercício, pude perceber que a professora segue técnicas de leitura baseadas nas concepções de linguagem de Neder (1992), onde a estratégia de interação verbal resulta na construção de sentido através de processos de leitura conjuntos, como a leitura silenciosa e a investigação linguística, produzindo uma análise linguística.

A verdadeira substância da linguagem não é constituída por um sistema abstrato de formas linguísticas, nem pela enunciação monológica isolada, nem pelo ato psicofilosófico de sua produção, mas pelo fenômeno social da interação verbal, realizada pela enunciação ou pelas enunciações. A interação verbal constitui, assim, a realidade fundamental da linguagem. (Neder, 1992:443); Bakhtin (1986:123)

A professora inicia, então, a aula verificando com a turma quem fez a atividade dirigida previamente para casa. O objetivo, como é apresentado no plano de aula ${ }^{1}$, é fixar o conteúdo estudado em sala por meio de correções de atividades. Ela também anuncia o que os alunos irão corrigir e o que estudarão em sala no dia atual. A professora afirma que o conteúdo será o estudo de texto através de mídias com a temática voltada à inclusão social. Ela pede aos alunos que abram o livro na página 79 e $8 \mathrm{o}^{2}$ e enuncia que o texto em análise para a atividade que fala sobre a diversidade social com foco no autismo. Ela, então, pede à turma por voluntários para responder à primeira questão. Alguns alunos levantam a mão e respondem. Ela ouve primeiramente à dois alunos e concorda com suas respostas, citando algumas ressalvas que poderiam ser melhor explicadas através de uma escolha melhor de palavras. Logo em seguida, ela seleciona mais dois alunos em lugares diferentes e também concorda com suas respostas, estas melhor colocadas que as anteriores. A professora escreve no quadro a resposta indicada pelo guia didático do professor. A docente segue a correção da atividade lendo as questões em voz alta, o texto em questão já fora lido silenciosamente previamente pela turma, e anotando ${ }^{3}$ as respostas no quadro. A professora estimula os alunos a responder de forma clara e objetiva, com sentido completo. Ela reforça esse aspecto pois outros professores de outras disciplinas reclamaram para ela que uma das grandes necessidades dos alunos dessas turmas observadas é a produção de sentenças de sentido completo sem faltar termos essenciais e acessórios fundamentais à compreensão. Ela também estimula a consciência crítica dos alunos ao citar um aluno da escola que se encontra na mesma condição psicológica do protagonista do texto analisado durante a atividade. Os alunos o conhecem e se mostram compreender a situação e condição através desse exemplo. Após essa reflexão, a professora dá continuidade à correção dos exercícios. Logo após a correção

das atividades interpretativas textuais, a professora faz perguntas de teor linguístico, indagando sobre vocabulário específico encontrado no texto. Tal vocabulário interfere 
diretamente na compreensão da mensagem central do texto, logo, ela utiliza de perguntas conceituais, a fim de que os alunos encontrem frases, expressões, sinônimos ou outros vocábulos que indiciem o significado das palavras de sentido ainda desconhecido pelos alunos, assim, eles fomentam a construção de sentido

durante a atividade. A professora então finaliza a primeira aula com a turma do $7^{\circ} 02$ e parte para a segunda aula geminada no $7^{\circ} 04$.

Ao chegar na sala do $7^{\circ}$ 04, a professora encontra seus alunos desorganizados e conversando entre si. E, logo chama a atenção da classe ao anunciar que na aula do dia, eles irão assistir a um filme cuja temática faz intertextualidade com o livro paradidático da etapa, cuja temática está voltada para o nazismo, o preconceito e dificuldades vividas pelos judeus em meados do século XX. Entretanto, a professora começa a aula corrigindo a atividade de análise linguística dirigida previamente para casa. Ela lê as perguntas em voz alta e pede a um aluno por vez que contribua com sua resposta. A professora então corrige oralmente e completa as respostas fornecidas pelos alunos. Ela explica como reconhecer uma crítica em uma charge ou texto imagético através da inferência de conhecimentos prévios para identificar novas mensagens ou morais implícitas no texto. No caso dessa atividade, há a referência de um garoto com deficiência física que critica os tratamentos recebidos pelos outros indivíduos ao redor dele. Com isso, a professora tenta estimular a consciência crítica dos alunos perante a sociedade e como é importante a igualdade e tratamento justo perante todos os indivíduos. Os alunos concordam com o discurso da professora e citam casos em que houve injustiça e eles depreciaram a atitude dos envolvidos perante a pessoa com limitações físicas.

Após a discussão sobre o texto da atividade interpretativa, a professora inicia a parte da aula referente à análise morfossintática do sujeito. Ela lê em voz alta a explicação relacionada ao ensino de sintaxe e da identificação do sujeito e predicado e dos tipos de sujeito. Ela relembra o conceito de concordância verbal e nominal através de exemplos no quadro para facilitar a identificação dos aspectos sintáticos em questão. Ela apresenta as conjugações verbais e chama atenção da turma para a identificação do tipo de sujeito desinencial referindo-se as desinências. Além disso, ela chama atenção para outros elementos encontradas no texto, como: modificadores, conectivos, estruturas paralelas, palavras-chave, exemplos e núcleos sintáticos, que são partículaschave que facilitam na identificação de termos sintáticos que fornecem pistas ao leitor para a construção autônoma de sentido. Essas partículas são consideradas indícios contextuais e são elementos que ajudam o leitor a determinar o possível significado de uma palavra desconhecida. Tal conceito é explorado por Deighton (1959). A professora explica os termos essenciais da oração e relembra o conceito de oração, frase e seus tipos. Ela escreve exemplos de frases com quatro tipos de sujeito apresentado pelo material didático da escola: simples, desinencial, oração sem sujeito e orações com sujeitos inferentes a palavras substantivadas, como pronomes, verbos e numerais. Ao utilizar desses exemplos, ela comenta dicas para auxiliar na identificação do sujeito por meio de perguntas acusativas, envolvendo apenas o verbo e suas ações, como em: quem parece? Vindo da frase "Ele parece com meu irmão." Logo, o termo acusativo, resposta da pergunta, é identificado como sujeito. Na maioria das vezes, os alunos acertaram as perguntas dos exercícios envolvendo análise linguística de sintaxe, 
comprovando a eficácia da técnica da professora. Após esse exercício controlado, a professora inicia um exercício cujos alunos têm de produzir frases com cada tipo de sujeito utilizando de palavras pré-dispostas pelo livro da disciplina. Logo após cinco minutos, a professora dá início a correção da atividade pedindo para oito alunos que compartilhassem de suas respostas. Os alunos respondem com suas produções e a

professora os corrige, utilizando de sua técnica de identificação do sujeito, pedindo a colaboração dos alunos para responder. Assim, em uníssono, os alunos se autocorrigiam ao responder as perguntas-conceito da professora. Ela encerra a correção das atividades e introduz a temática do filme "A vida é Bela", que os alunos assistirão no período seguinte, após o intervalo diário.

Durante o momento em que é assistido o filme, a professora faz breves pausas para iniciar pequenas discussões sobre as temáticas que o filme envolve, tais quais o caos social estabelecido pelo nazismo, as situações de perigo envolvendo crianças e idosos e o preconceito racial envolvendo negros e judeus. A professora tenta inferir diversas interpretações para os alunos durante as cenas. Entretanto, ela não faz perguntas diretas aos alunos sobre a temática e interpretação. Ela expõe as possíveis inferências aos alunos, impossibilitando a produção autônoma de sentido sobre as cenas e a moral inserida no contexto apresentado. Após direcionamentos, a professora cita suas últimas considerações para que os alunos se atentem à detalhes importantes à correlação que os alunos irão inferir ao apresentar seu estudo da leitura do livro paradidático da etapa. A aula finaliza com o final do filme e uma rápida análise dos fatores em comum entre a obra audiovisual e o livro paradidático.

\section{I.I O corpo discente}

Para a análise de observação referente aos alunos, separei o segundo dia de minha investigação para tal tarefa. Vale lembrar que cada sala possui em torno de trinta a quarenta alunos, onde eles são organizados em sete fileiras horizontais por sete fileiras verticais, sendo a primeira fileira horizontal voltada para o quadro branco. Essa missão aconteceu durante o período matutino do dia quatorze de junho. Tais observações foram feitas com oito alunos em aulas geminadas, das sete e dez às oito e cinquenta da manhã, sendo quatro alunos da turma $7^{\circ} 02$ e outros quatro do $7^{\circ} 04$. O tempo reservado para cada aluno levou em torno de três a cinco minutos por

aluno observados durante a realização e correção de exercícios, momento de explicação do conteúdo pela professora e durante a passagem do filme utilizado para construção de intertextualidade com o livro paradidático da etapa, "A mala de Hana" (Levine, Karen).

\section{Ao visitar $07^{\circ} 02$}

Durante a explicação da professora, um aluno que se encontra na primeira fileira no canto direito próximo ao quadro repousa a cabeça, observa o professor escrever no quadro e anota os exemplos do quadro no caderno. Tal ação se repete ao longo dos três minutos de observação dedicados a esse aluno. 
Já um aluno que se localiza na última fileira no canto inferior esquerdo, próximo ao canto da sala em que me encontrava, copia as respostas do exercício que estava sendo corrigido, enquanto conversava paralelamente com um colega. Em seguida ele divaga, olhando para os lados, para o teto da sala e, logo em seguida, volta a copiar as respostas do quadro.

Outro aluno, que se encontra no centro da sala, enquanto a professora explica seus exemplos e respostas no quadro, conversa paralelamente, lê o caderno do colega, e então levanta o braço. A professora cede a vez ao aluno, e ele indaga a diferença entre

sujeito simples e sujeitos substantivados, assunto do capítulo do exercício estudado no momento. A professora explica a diferença entre as categorias utilizando exemplos e estimulando a aluna a construir significado ao identificar os termos sintáticos analisados como sujeito das orações. Em seguida a aluna anota em seu caderno suas correções e continua prestando atenção à explicação da professora.

Enquanto a professora explica as definições dos tipos de sujeitos durante a análise sintática junto com técnicas de inferência de indícios contextuais, uma aluna no canto superior esquerdo, na segunda fileira horizontal e segunda fileira vertical, próximo à mesa da professora, permanece de cabeça baixa, porém segue anotando em seu livro as respostas do quadro. Ela levanta a mão para perguntar. A professora, por sua vez, cede a vez de fala à aluna e ela pergunta se num exemplo dado anteriormente havia uma oração sem sujeito. A professora recorre ao quadro branco e escreve um exemplo. Ela identifica todos os termos lexicais da oração conjuntamente com os alunos a fim de induzir uma construção de percepção analítica sintática autônoma através de um exercício prático guiado. Assim, a professora conclui sua explicação com a aluna se autocorrigindo e anotando a resposta correta em seu livro.

\section{Ao visitar $07^{\circ} 04$}

Ao início da aula, a professora pergunta aos alunos a interrelação temática entre o filme assistido pela turma e o livro paradidático da etapa. Uma aluna na terceira fileira horizontal ao centro da sala, estende a mão para cima a fim de responder a indagação da professora e comenta que as motivações para superar os desafios é a mesma. A professora concorda com a aluna e complementa a informação dada pela aluna fornecendo mais aspectos comparativos sobre as duas obras, como as marcas de estrela utilizada pelos judeus como método de identificação racial, o que trazia tristeza para os protagonistas das obras.

Já um aluno na quarta fileira horizontal e sexta fileira vertical, próximo à mesa da professora, levanta a mão para indagar. A professora cede a vez de fala e o aluno a pergunta se entendeu corretamente um aspecto comparativo analisado por ele. Ela concorda com o aluno, adiciona algumas correções e o aluno anota o que lhe foi dito.

Um outro aluno na segunda fileira vertical, ao lado esquerdo, comenta para a turma sua experiência durante uma viagem à Alemanha, em Auschwits, e fornece detalhes dos marcos históricos os quais visitou, que são referências à lugares específicos na história do paradidático "A mala de Hana”. A professora então comenta e estimula a consciência crítica dos alunos, construindo com eles, a partir dos comentários discutidos em sala, sobre o tema do racismo e preconceito social. 
Ao final, um aluno na primeira fileira horizontal e quinta fileira vertical, à direita, se encontra divagando, não abriu o livro em nenhum momento da aula, seguiu apenas escutando a professora durante toda a aula. A professora percebe a inércia do aluno e o pede para abrir o livro. Ele então abre o livro e inicia a resolução da atividade de análise linguística realizada anteriormente em sala.

\section{I.I O material didático e seus enfoques}

Sobre o material didático adotado, que provém da própria editora da instituição denominada SAS. Fundado em 2004, o SAS é uma plataforma de educação que

desenvolve conteúdo, tecnologia e serviços de excelência para mais de 700 escolas e 230 mil alunos no Brasil. Da educação infantil ao Ensino Médio, o SAS oferece às suas escolas parceiras soluções educacionais, como livros didáticos, consultoria pedagógica e produtos que integram tecnologia e conteúdo pedagógico. $\mathrm{O}$ auxílio de professores e gestores na tarefa da potencialização do aprendizado e desenvolvimento das habilidades dos alunos são ferramentas para ajudar o aluno a enfrentar os desafios de suas vidas, dentro e fora de sala de aula. Desta forma, a renovação de conteúdo e abordagens, atualizando dados e informações novas é crucial.

O material didático em questão para minha investigação foi o Livro 2 de Língua Portuguesa - SAS, Gramática: teoria e atividades - FTD para o $7^{\circ}$ ano Coleção Fundamental. Esse manual traz consigo capítulos que envolvem compreensão textual, fomentação de consciência crítica explicações de conteúdo linguístico morfossintático, como também atividades voltadas ao ensino de produção textual e seus gêneros-base: narrativo, descritivo, argumentativo, expositivo, injuntivo e dialogal. Tais conceitos aparecem nas bases teóricas da noção de sequência textual na análise pragmático-textual de Adam, Jean-Michel propostos por Bonini (2005). Este livro tem como expectativas de aprendizagem: ler e interpretar textos; apresentar diferentes opiniões sobre os temas dos capítulos; identificar o sentido de palavras, expressões e estruturas pragmáticas; estabelecer relações entre variados textos com enfoque em um mesmo tema trazido nos capítulos; realizar leituras inferenciais, usar o dicionário para eximir dúvidas quanto ao vocabulário; refletir sobre temas sociohistórico-político-linguístico; e reconhecer informações explícitas e implícitas do texto por meio de palavras e expressões.

O livro didático em questão traz notas de rodapé para o docente utilizar como guia em sua metodologia em sala de aula. As metodologias envolvem leitura silenciosa; leitura coletiva; promoção de discussões dos assuntos propostos pelos capítulos por meio de perguntas pré-dispostas nas atividades; associação de uso de vocábulos, expressões e estruturas pragmáticas e morfossintáticas na linguagem oral e escrita;

exposição de frases em diversos modos-temporais; e envolvem, também, análises morfossintáticas por meio de realização de exercícios com explicação de conteúdo por meio de discussões em grupo.

As páginas observadas em minha investigação são referentes ao capítulo Io. Neste capítulo é trabalhado como conteúdo linguístico a morfossintaxe do sujeito, através de atividades pré-determinadas pelo livro voltadas à analise linguística; como também, na parte de interpretação textual é trabalhada a temática da inclusão social através de dois textos: I. Adolescentes com autismo surpreende seus pais ao escrever 
uma carta profunda e sensível sobre pessoas com autismo" e 2. Inclusão Social. Quanto ao conteúdo linguístico, o objetivo principal era analisar a morfossintaxe do sujeito e revisar as classes gramaticais que podem exercer a função de sujeito, recapitulando os conteúdos estudados previamente. Todos esses processos foram realizados através da fixação do conteúdo estudado em sala por meio de correções de atividades, revisando os aspectos linguísticos analisados junto com explicações do conteúdo. As páginas em questão são setenta e nove e oitenta, focadas em exercícios de interpretação textual; oitenta e um, voltada à realização de exercícios de análise linguística; páginas oitenta e cinco e oitenta e sete referentes a exercícios de análise e fixação de conteúdo, respectivamente; enquanto a página oitenta e seis remete à explicação de conteúdo com exemplos; e, por fim, página oitenta e oito, que é voltada a exercícios de análise morfossintática.

\section{CONCLUSÃO}

Ao final do meu período de observação, pude concluir que a leitura é realizada de diversas maneiras e permeia por muitos caminhos de realização. $O$ trabalho associativo-inferencial realizado pela professora, juntamente com a articulação e adaptação do material didático, além do uso de recursos extralinguísticos para fomentação da consciência crítica e adição de conteúdo extra para os alunos, foi bem sucedido e alcançou os objetivos previstos tanto pelo plano de aula do cronograma da instituição, como pelas diretrizes, que foram estudadas por mim em sala de aula na Universidade Federal do Ceará (UFC) durante a disciplina de Estágio de Ensino de Leitura, as quais levei em consideração para a realização desta investigação.

No que diz respeito a ação da professora, ressalta-se a criatividade e atitude interventiva de trabalhar os conteúdos programáticos de uma forma dinâmica, coletiva e conscientizadora. Entretanto, para as atividades relacionadas a leitura, a professora poderia ter fornecido mais oportunidades de leitura a fim de induzir a construção autônoma de sentido e aquisição de conhecimento novo, mas o que foi realizado foi logrado com sucesso pelos alunos. Ela trabalhou a competência textual e gramatical dos alunos ao facilitar a produção e compreensão de textos em situações de interação e no reconhecimento de estruturas coerentes com a língua, semântica e local de fala. A professora também exercitou as capacidades da competência textual com os alunos. Dentre elas, a capacidade formativa, a qual possibilita os alunos produzir e compreender textos e avaliá-los perante sua formação e uso; a capacidade

transformativa, em que possibilita aos alunos modificarem um texto e avaliarem se as modificações estão adequadas no texto através de técnicas de retextualização, o qual foi realizada por meio de textos escritos e charges; e, não inteiramente lograda, mas identificável durante o processo de leitura, a capacidade qualificativa, em que possibilita aos alunos relacionarem a que tipo ou gênero textual pertence um texto.

Sobre o material, este me pareceu completo, pois apresenta textos distintos sobre a mesma temática para que os alunos possam construir suas opiniões a partir de diferentes pontos de vista e abordagens. Os exercícios são relevantes à leitura, pois são objetivos e discursivos, gerando oportunidades de discussões que auxiliam na investigação e aprendizagem do conteúdo previsto. Os textos possuem linguagem acessível com termos específicos para induzir a construção de sentido através da aquisição de novas terminologias e vocábulos. 
Acerca dos alunos observados, avaliei que, durante o processo de leitura de textos escritos, eles sabem selecionar textos segundo sua necessidade; leem de maneira autônoma textos de gêneros e temas diferentes, construindo familiaridade ao selecionar procedimentos adequados a objetivos e interesses; desenvolveram a capacidade de construir pressuposições de sentidos, forma e função do texto; utilizaram de inferências pragmáticas para dar sentido a expressões que não pertenciam a seu banco linguístico; extraíram informações implícitas, apoiando-se em suposições e deduções; como também integraram e sintetizaram informações expressando-as em linguagem própria, não inteiramente desenvolvida linguisticamente, mas compreensível. E, ao fim, foram capazes de interpretar recursos figurativos como metáforas, eufemismos e intertextualidades. Sobre o processo de análise linguística, os alunos foram capazes de constituir um conjunto de conhecimentos sobre o funcionamento da linguagem e sobre o sistema linguístico relevante para a prática de escrita, leitura e produção de textos, cujo conteúdo em questão foi a análise morfossintático do sujeito e seus tipos; além disso, os alunos delimitaram e identificaram unidades, compreendendo as relações estabelecidas entre as unidades, termos e funções discursivas associadas a elas no contexto em questão. Ao final, eles foram capazes de questionar a realidade formulando problemas e os resolvendo, utilizando o pensamento lógico, a criatividade e a capacidade de análise crítica, verificando sua adequação.

Por fim, essa experiência de estágio foi muito proveitosa e engrandecedora para a fomentação e aquisição de conhecimento relacionado ao exercício da docência. Com este relatório, fui capaz de analisar que pontos são essenciais durante a prática do ensino, considerando as habilidades e capacidades humanas na aquisição, análise e construção de sentido e conteúdo através de diferentes recursos utilizados na rotina dos alunos do $7^{\circ}$ ano do Ensino Fundamental II.

\section{ANEXOS}

Imagens das turmas

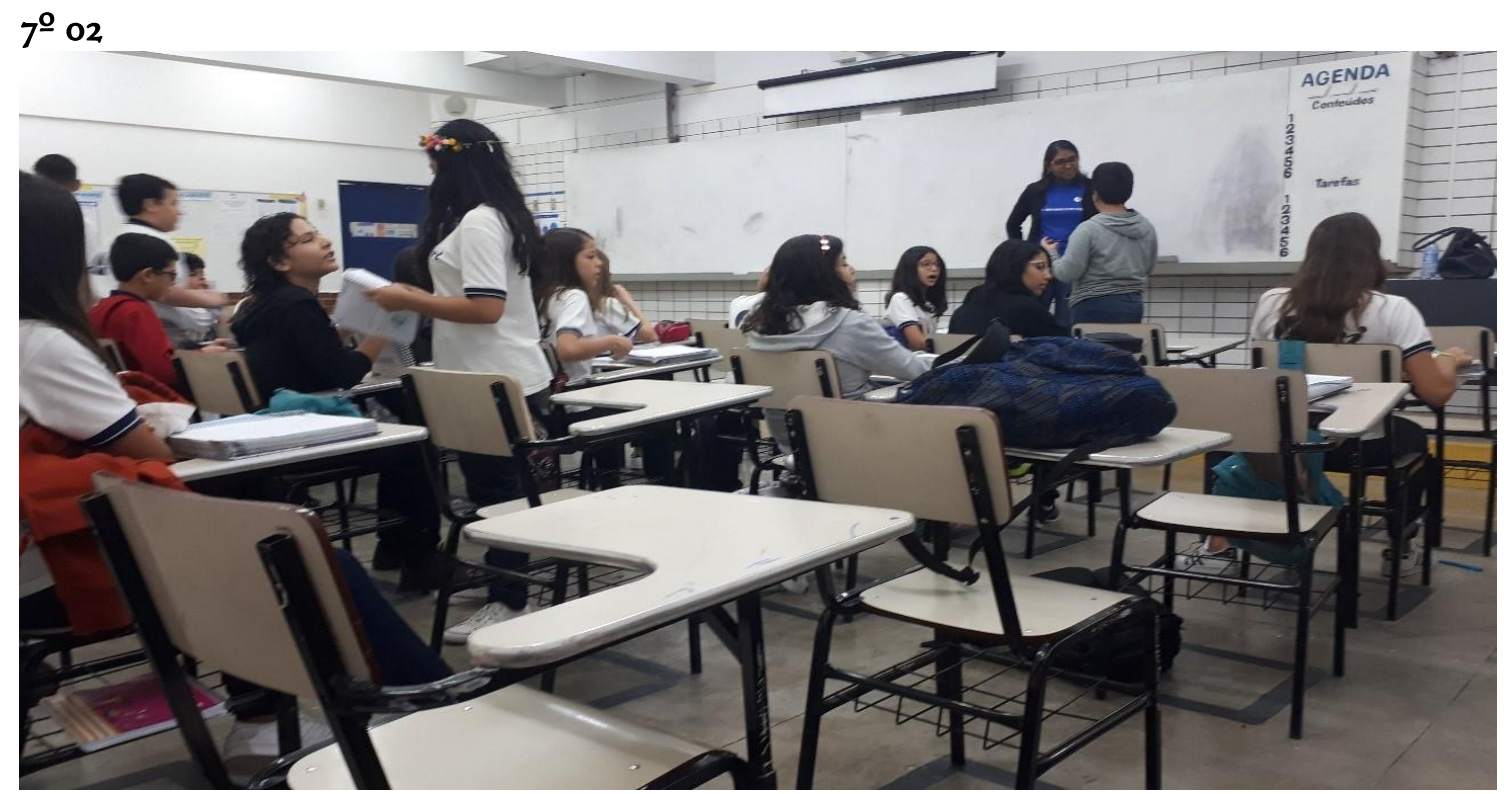


Revista Ibero- Americana de Humanidades, Ciências e Educação- REASE Open Coccess

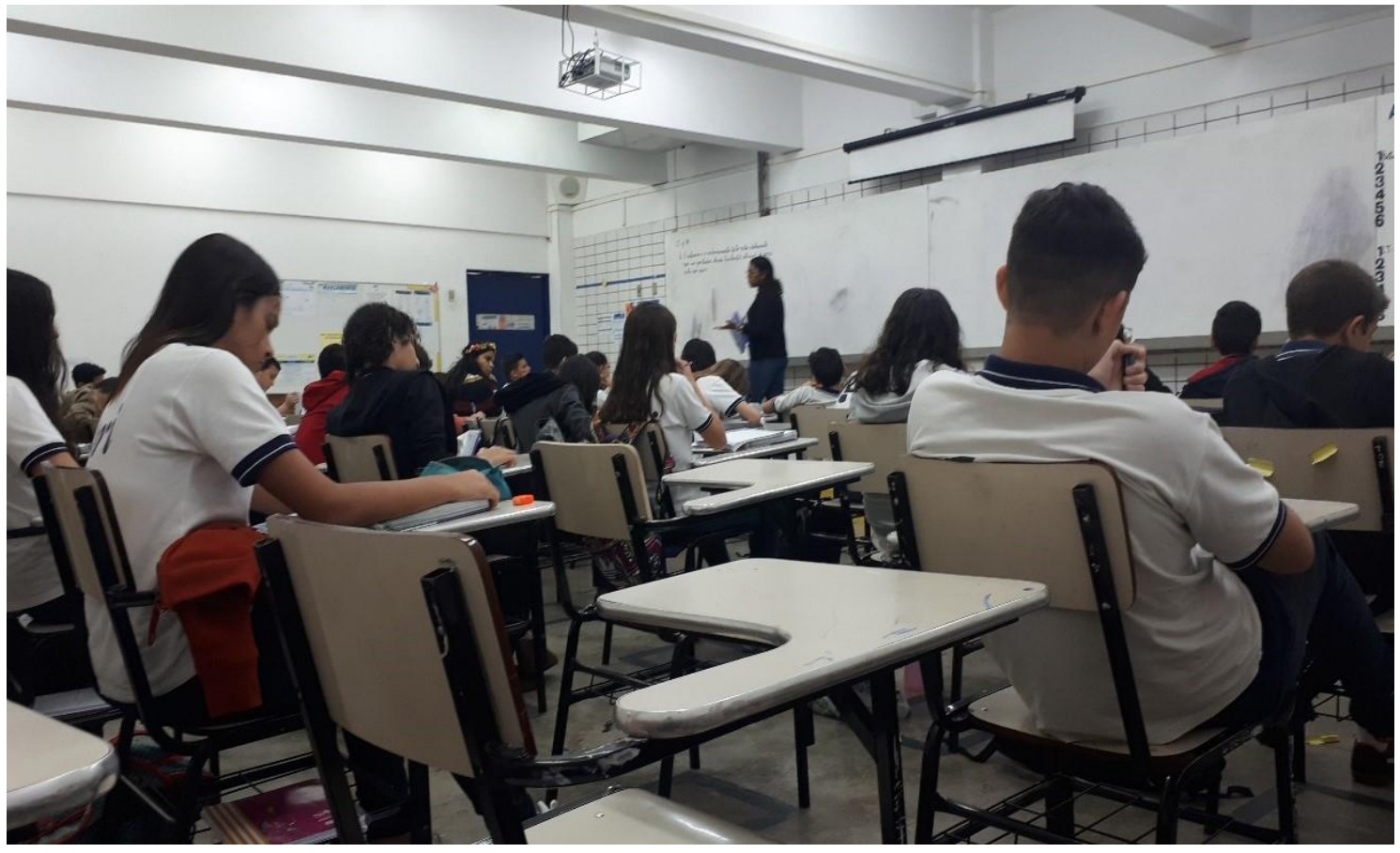

$7^{\circ} 04$

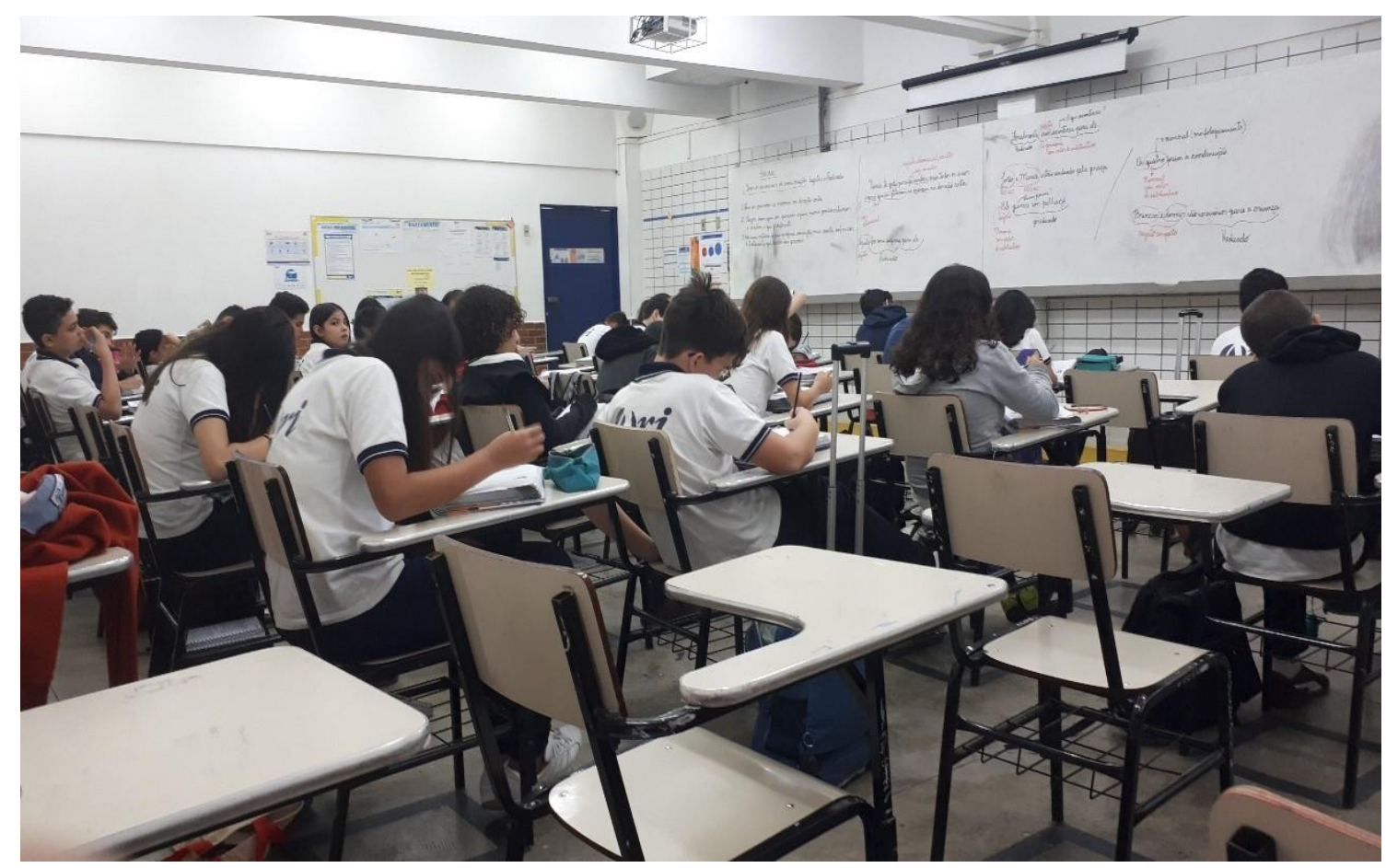




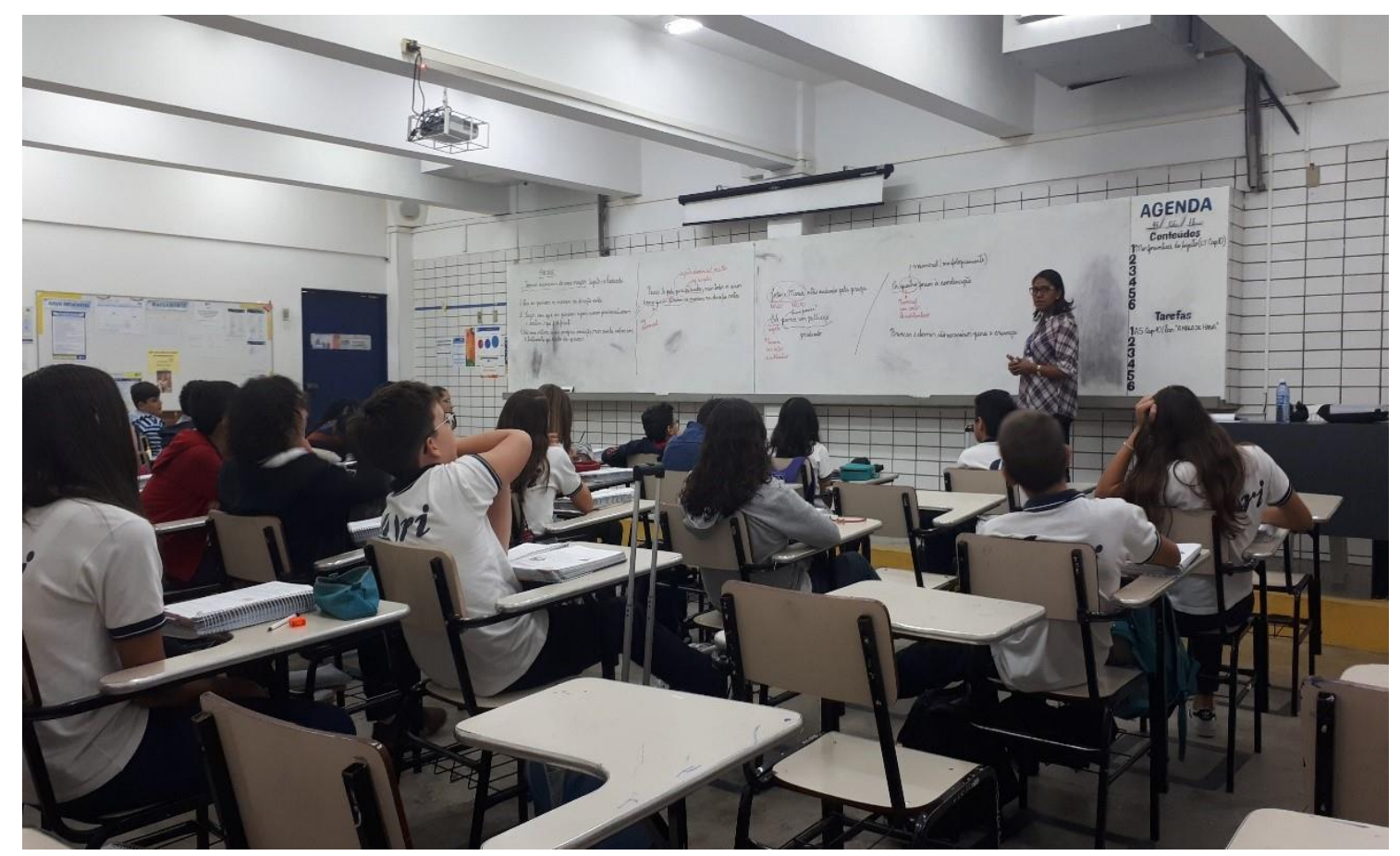

Livro didático da turma:

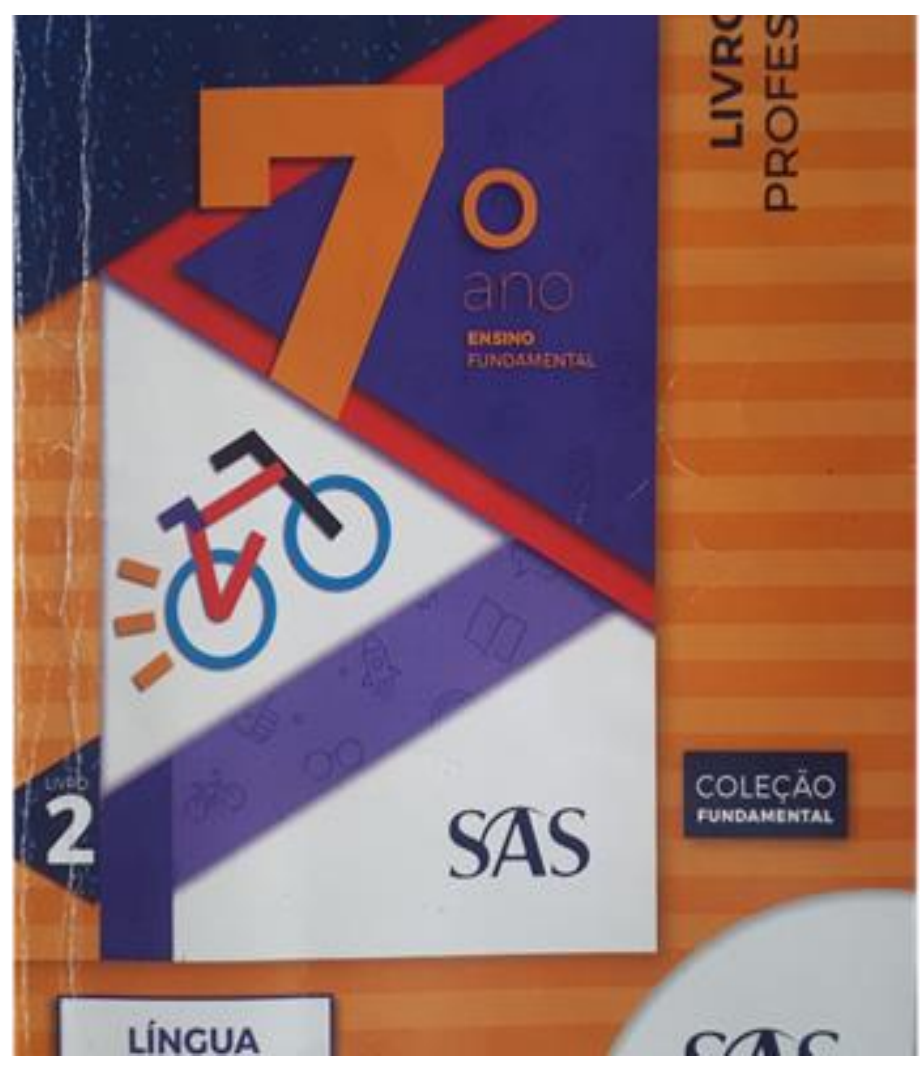


Páginas comtempladas nas aulas:

- p. 79 - exercício de interpretação textual

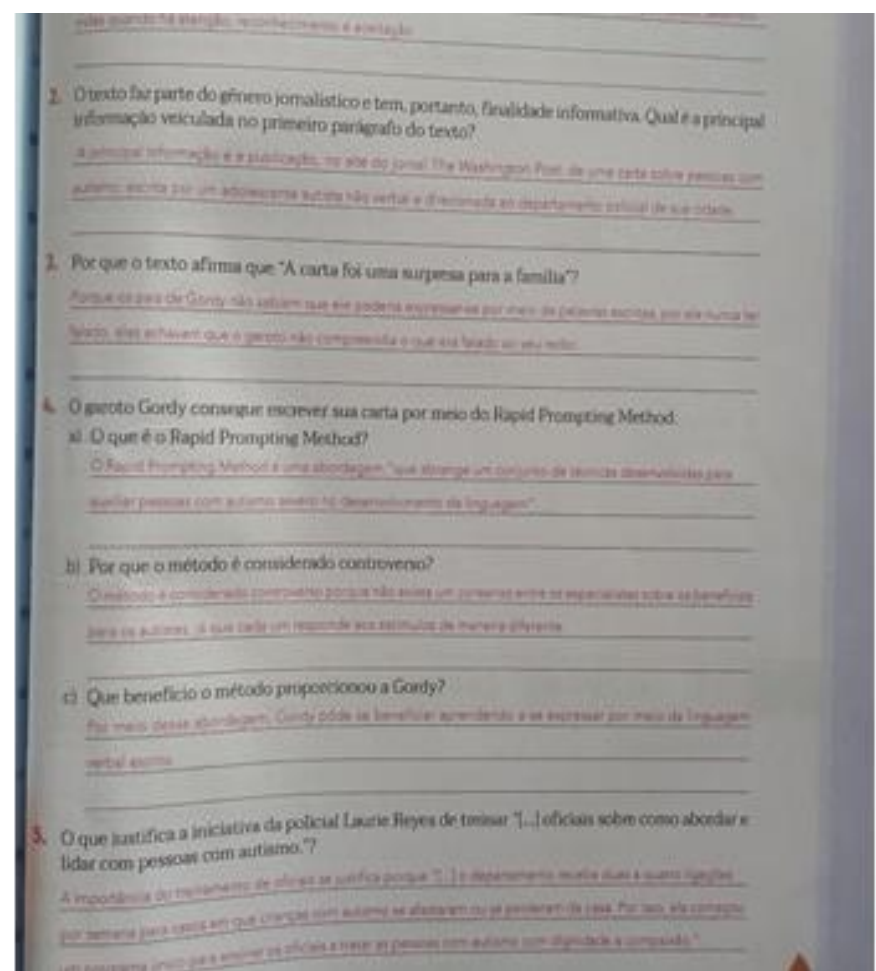

p. 8 o - exercício de interpretação textual

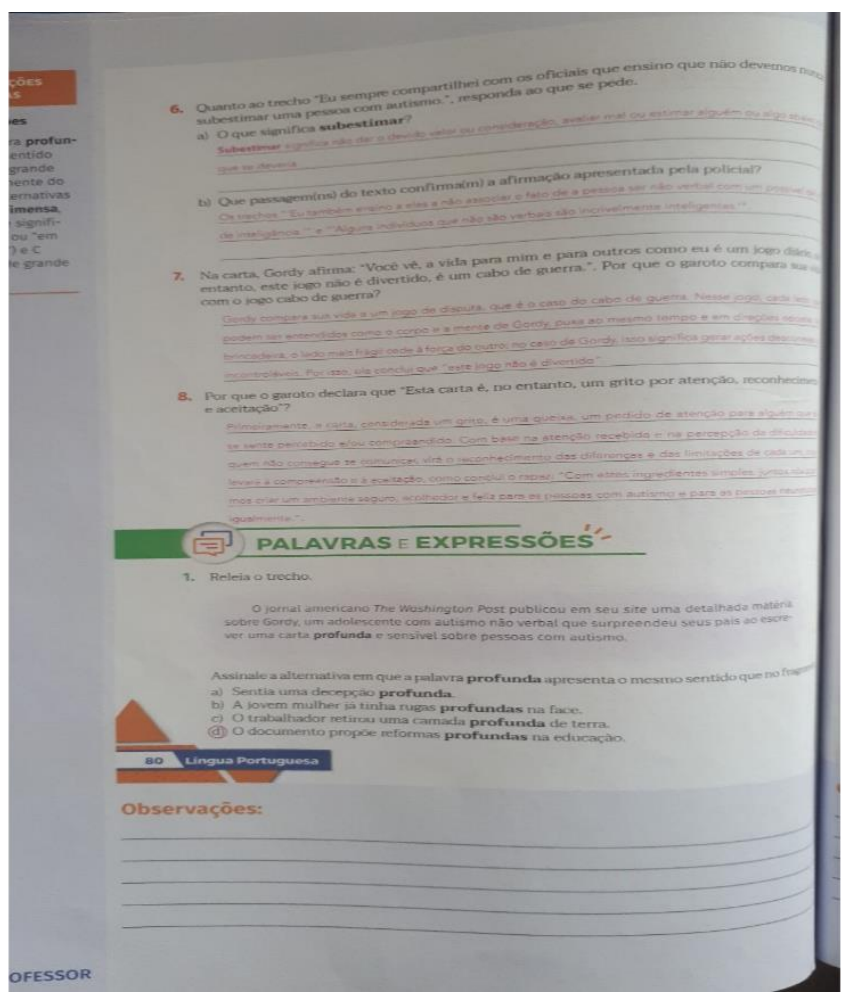


p. 8I - exercício de ressignificação lexical

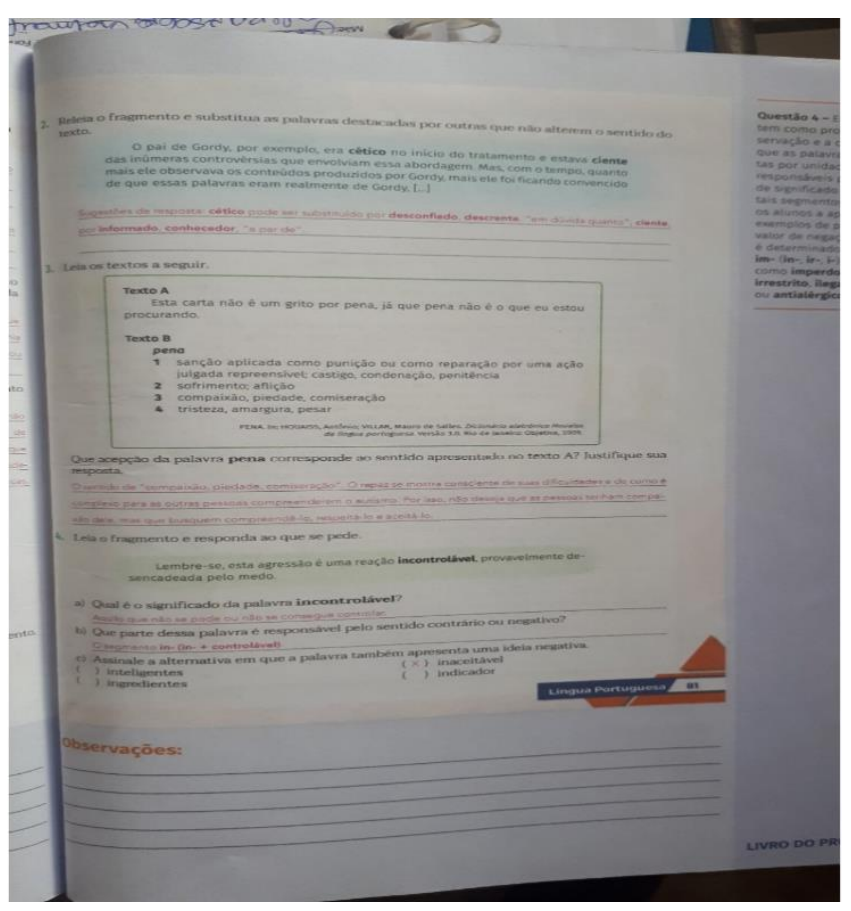

p. 85-exercício de análise linguística através de charges

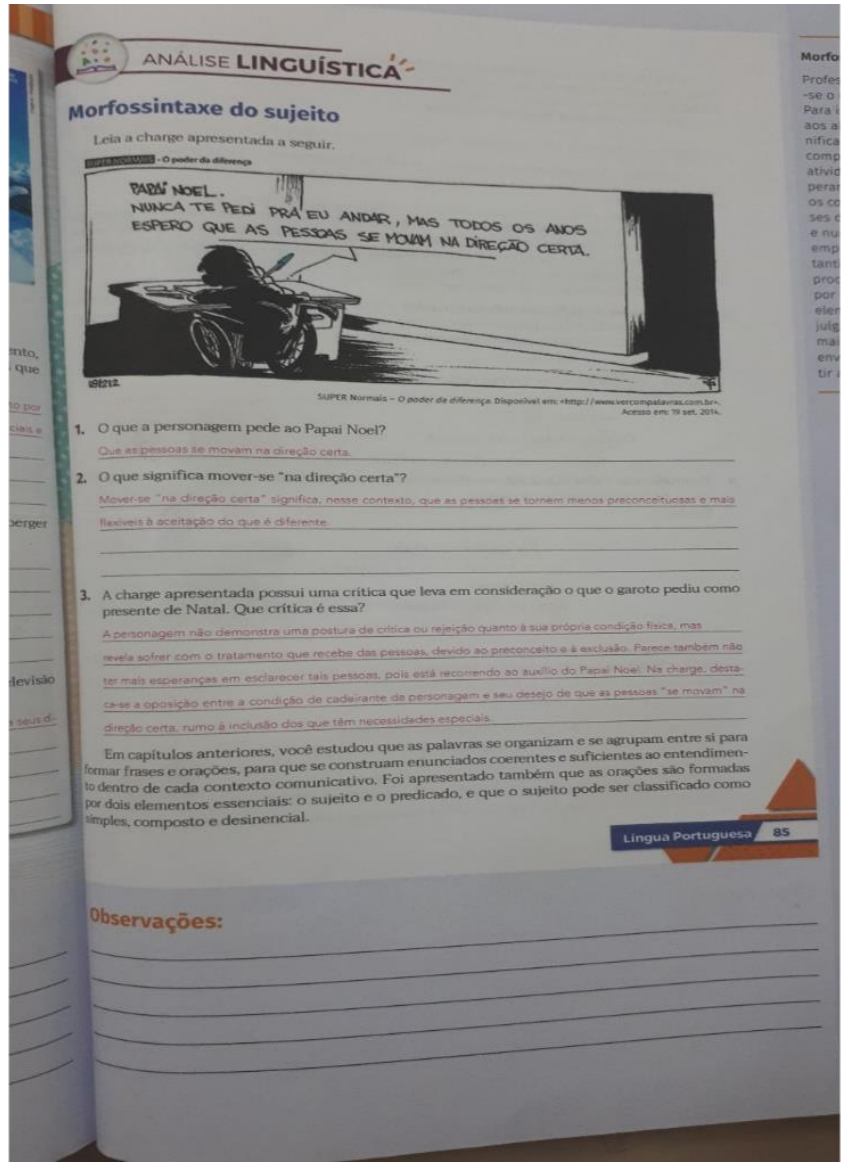


p. 86 - conteúdo linguístico explorado em sala

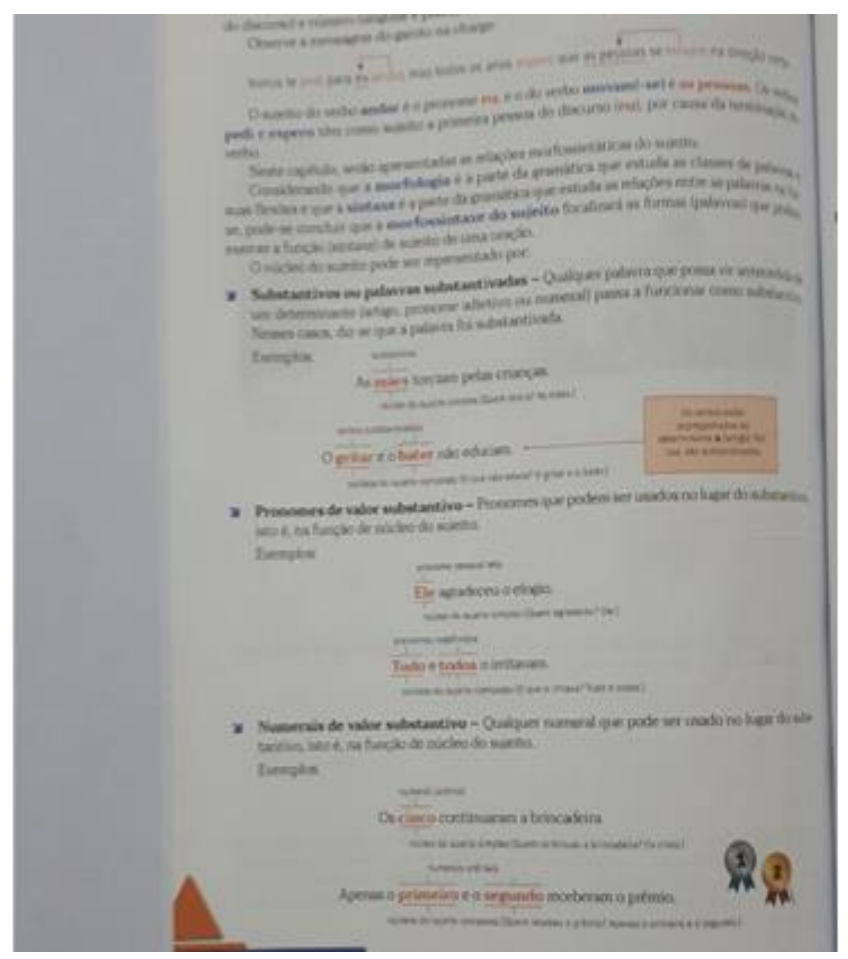

p. 87 - exercício de fixação de conteúdo e análise linguística através da prática livre

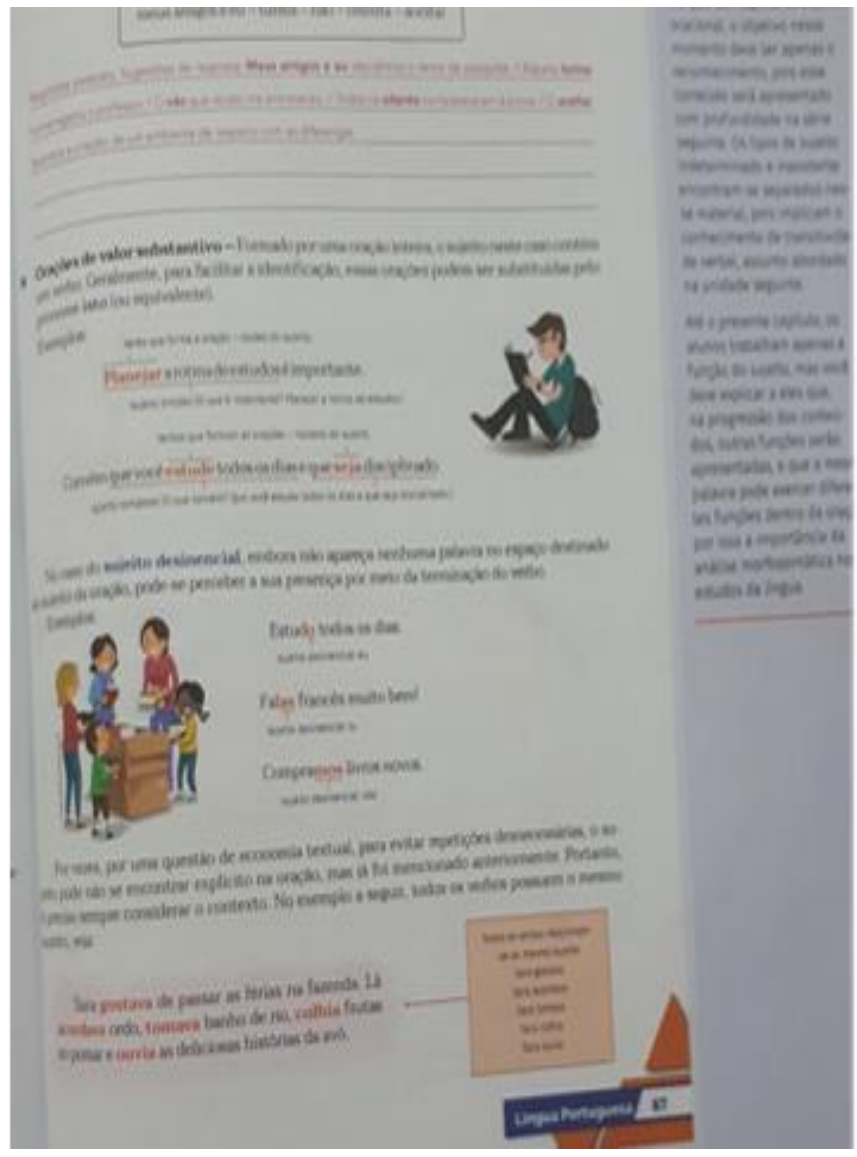


- p. 88 - exercício de análise linguística

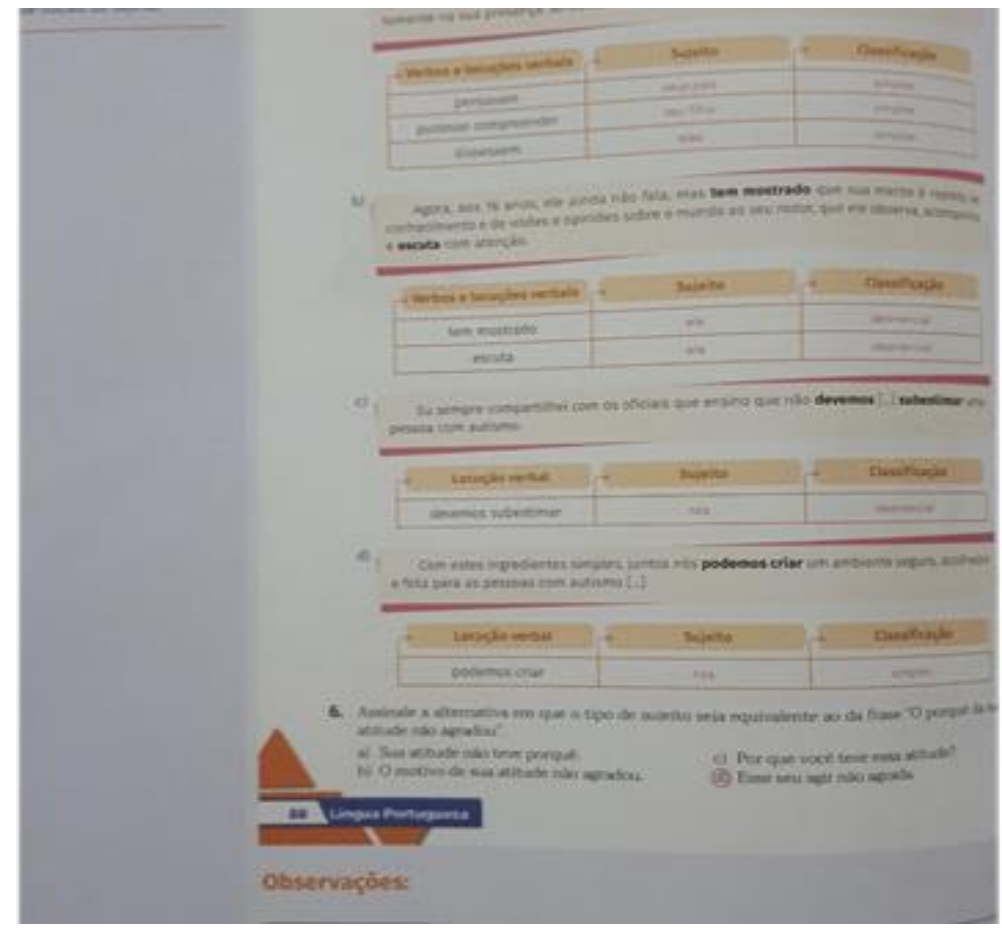

Imagem do plano de aula para o Capítulo ıo - Diferença que ensina

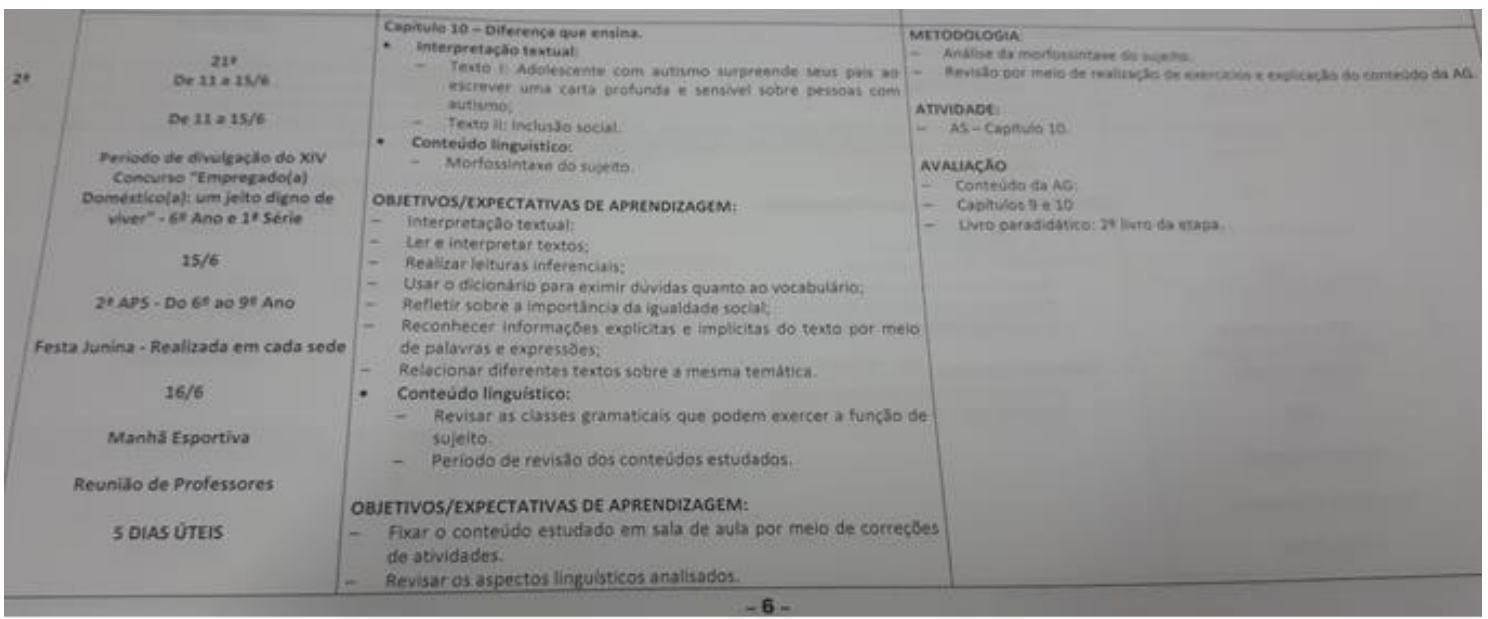

\section{REFERÊNCIAS}

BONINI, Adair. A noção de sequência textual na análise pragmático-textual de JeanMichel Adam. In: MEURER, José Luiz, BONINI Adair; MOTTA-ROTH, Desirée (Orgs.). Gêneros: teorias, métodos, debates. São Paulo: Parábola Editorial, 2005.

BRASIL, Secretaria de Educação Fundamental. Parâmetros Curriculares Nacionais: terceiro e quarto ciclos do ensino fundamental - língua portuguesa. Brasília: $\mathrm{MEC} / \mathrm{SEF}$ da Educação. 1998. p.7-8/32-33/49-52. 
MOREIRA, Nadja da Costa Ribeiro. "Orientações para o ensino da leitura" In: Revista de Letras. № 7. Fortaleza, jan/dez; 1984.

TRA VAGLIA, Luiz Carlos. Gramática e interação: uma proposta para o ensino de gramática no 으 e 2으 graus. São Paulo: Cortez, 1997.

7ํㅜㅅNO ENSINO FUNDAMENTAL - LIVRO 2, Fortaleza: SAS, 2015.

Disponível em: http://www.aridesa.com.br/pagina/institucional/historico.aspx. Acesso em: 16 de junho de 2018.

Disponível em: http://novo.portalsas.com.br/. Acesso em: i7 de junho de 2018. 